\title{
SISTEMA DE TREINAMENTO COLABORATIVO EM EDUCAÇÃO BASEADA EM PROJETOS ${ }^{1}$
}

\section{COLLABORATIVE TRAINING SYSTEM IN PROJECT-BASED EDUCATION}

\author{
Jairit Garavit ${ }^{2}$ \\ https://orcid.org/0000-0003-1976-9891
}

1. ¿Este produto é o resultado do trabalho árduo de uma de suas Linhas de Pesquisa do projeto "Como deve pesquisar em Educação virtual e a distância?" do ano de 2021, realizada com Membros de forma interdisciplinar e interinstitucional (Professores - Alunos) da Pesquisa Seedbed: Sistemas Integrados de Gestão "Integradoss" Anexados ao GrupLAC: SIGCIENTY da Universidade Nacional Aberta e a Distância UNAD.

2. Engenheiro Industrial, Especialista em Educação Superior e à Distância, Mestre em Sistemas Integrados de Gestão HSEQ-RSC, Revisor de Pares da Elsevier, Revisor de Pares da Publons Academy e Advisor \& Peer Rewiever de Mendeley, Editor de Currículo em Revistas Acadêmicas - Minciencias. Líder da Seedbed de Pesquisa "Integradoss" e nomeado Professor Pesquisador da Escola de Ciências Básicas, Tecnologias e Engenharia ECBTI. Zona Caribenha, na Universidade Nacional Aberta e a Distância - UNAD. Email institucional Jairit.Garavit@unad.edu.co

Projeto de Pesquisa: ¿Cómo pesquisar em Educação virtual e a distância? 
Resumo: Os resultados dos alunos são melhores quando o treinamento baseado em estudos de caso e problemas são combinados, e o treinamento é apoiado pelo gerenciamento de projetos, com a solução de problemas no centro do treinamento Ao aplicar uma pedagogia por projeto, $\mathrm{O}$ tema da pedagogia e do projeto ocupa um vasto campo, cuja exploração continua a ser fascinante numa época em que a noção de projeto se torna central em qualquer discurso educacional para quem a pedagogia do projeto se torna uma pedagogia de libertação na nova educação. A abordagem do projeto não é, em sua essência, uma técnica ou uma forma específica de ensino. Pelo contrário, é uma forma de pensar o ensino com vista a uma aprendizagem que se espera melhorar, colocandose ao lado do ensino da aprendizagem na ação, pelo aluno como líder da sua formação e pelo professor como seu vigilante. É preciso dizer que a abordagem do projeto é ideológica e não uma moda ou uma fórmula educacional em sentido estrito.

Palavras chaves: ABPr, Aprender a aprender, Pedagogia por projeto, Abordagem do projeto, Gestão do projeto.

Abstract: Student results are better when training based on case studies and problems are combined, and training supported by project management, with problem solving being the center of training when applying a pedagogy per project, The topic of pedagogy and project occupies a vast field, the exploration of which is still fascinating at a time when the notion of project becomes central in any educational discourse for whom the pedagogy of the project becomes a pedagogy of liberation in the new education. The project approach is not, at its core, a technique or a specific way of teaching. Rather, it is a way of thinking about teaching with a view to learning that is expected to improve, taking sides with the teaching of learning in action, by the student as the leader of their training and by the teacher as their watchdog. It must be said, the approach of the project is ideological rather than a fashion or an educational formula in the strict sense.

Keywords: ABPr, learn to learn, Pedagogy by project, Project approach, Project management.

\section{Introdução}

Entre os muitos métodos que podem otimizar a urgência do aluno, a pedagogia baseada em projetos tem sido citada com frequência por várias décadas. Tornou-se uma prática diária na educação profissional e no ensino superior e foi introduzida em outros tipos de fluxos em certos países (por exemplo, na América Latina por meio de trabalho pessoal supervisionado. Ou rotas de descoberta, ou na Colômbia. No entanto, pedagogia baseada em projetos não é novidade, pois começa a ser aplicado no início do ano letivo, remontando aos anos 1960 e 1970, dependendo do país, e se impondo discreta mas com segurança no terreno da escola durante os últimos trinta anos. 
Este interesse renovado pela pedagogia baseada em projetos baseia-se nas possibilidades que oferece para se aventurar além das disciplinas, e assim mobilizar as competências transversais dos alunos e utilizar as TIC a vários níveis (para facilitar a pesquisa de informação, gestão do próprio projeto ou intercâmbio com colegas, incluindo autoavaliação e avaliação por pares). Esta pedagogia também se insere num quadro global de integração das iniciativas dos atores em torno do seu projeto de implantação, elemento essencial das políticas de autonomia. Por fim, busca familiarizar os alunos com a complexidade do mundo profissional atual, ajudando-os a construir um projeto pessoal e profissional durante a escolaridade.

Portanto, este método de ensino nem sempre parece ser de fácil aplicação, principalmente em termos de tempo e investimento necessário para a realização do projeto. Aprender por meio da solução de problemas, que às vezes é confundido com abordagem de projeto, é geralmente preferido. Por que é tão difícil de configurar? Isso agrega valor aos alunos em seu progresso e treinamento? Essas questões estão no cerne deste capítulo que tentará esclarecer o lugar e as especificidades da aprendizagem baseada em projetos entre as chamadas abordagens centradas no aluno e dar exemplos de implementação em diferentes níveis escolares, por meio de alguns resultados. efeitos da pedagogia baseada em projetos na aprendizagem, bem como as suas dificuldades de aplicação.

\section{As costuras dos projetos dos alunos}

A noção de projeto é amplamente utilizada no sistema educacional e abrange realidades muito diversas, como projetos escolares, projetos de ação educativa, projetos pessoais de alunos, etc. Cada um tem sua própria ideia do que é um projeto e como ele pode ser executado. O objetivo pode ser preparar concretamente os alunos para sua futura profissão, motivá-los por meio de realizações materiais, ou encorajar professores de diferentes disciplinas a trabalhar em equipe, ou desenvolver uma abordagem baseada em habilidades.

Vamos examinar mais de perto essa noção e como ela tem prevalecido no mundo escolar, antes de nos concentrarmos mais especificamente na formação alicerçada na gestão de projetos, uma modalidade ativa que traz sua cota de esperança para a motivação dos alunos, alunos e a apreensão do mundo complexo em que vivemos.

\section{Uma definição muito ampla do projeto}

Para definir pedagogia ou aprendizagem baseada em projetos, é necessário primeiro definir a noção de projeto próprio, noção bastante recente, pois só prevaleceu em nossas ações em meados do século XX, depois de pouco uso. E caprichosa até o século 19 (Champy \& Étévé, 2005). No nosso dia a dia, os projetos nos invadem: projetos de futuro, projetos profissionais ou projetos escolares de vários tipos, conversões, chamadas de projetos em laboratórios de pesquisa, etc., a tal 
ponto que é possível pensar que a presença de projetos e seu número se tornou praticamente o padrão para medir o dinamismo de empresas ou organizações acadêmicas.

Para Boutinet (2005), o projeto só existe por meio de uma materialização da intenção, que ao ser realizada deixa de existir como tal. Visualiza uma tensão inerente à noção de projeto, que traduz ao mesmo tempo e no mesmo movimento um certo reconhecimento da razão operacional e uma certa impotência da razão histórica para controlar o que ela implementou. Para ele, o projeto é mais do que um conceito, uma figura emblemática da nossa modernidade. Como podemos perceber, o uso extensivo do termo e seu amplo significado o tornam um objeto de estudo complexo e multifacetado que pode ser abordado de diferentes maneiras. Limitar-nos-emos aqui às características dos projetos dirigidos no âmbito escolar.

\section{Enunciação do termo projeto.}

El primer significado de la palabra proyecto (que proviene, del latín projicio, lanzar adelante, expulsar) en la definición que indica que se trata de la imagen de una situación, de un estado que creemos haber llegado, introduciendo el hecho de que todo queda por fazer. Essa definição que data do século XV é esclarecida pela maneira como pensamos para lidar e apreender um problema, que coloca o conceito de problema e de planejamento no centro do nosso tema. $\mathrm{O}$ outro significado da palavra, que data do século XVII, indica Trabalho, uma escrita preparatória; um primeiro estado, que acrescenta uma dimensão mais concreta a essa noção.

Para Boutinet (2005), o significado moderno de projeto teria suas raízes na nova concepção de arquitetura da época do Renascimento italiano e teria sido afirmado no contexto do Iluminismo, a partir das noções de progresso e ciência e técnica. desenvolvimento.

\section{A ordem do paradigma em projetos}

Um projeto existiria com o preceito do paradigma, promovendo a atividade concreta e organizada de um sujeito preocupado em estabelecer uma meta e os meios adequados para alcançála (Champy \& Étévé, 2005).

Ardoino e Berger (1989) detalham ainda mais essa noção: é, antes de tudo, uma intenção filosófica ou política, um fim, sempre, necessariamente, indeterminadamente, afirmando valores

em busca de realização. É, só então, a tradução estratégica, operacional, medida, determinada de tal objetivo. O projeto é a prefiguração mais exata possível, portanto, determinada e definida, do que antecipamos, definição na qual encontramos o compromisso do sujeito, o planejamento necessário e o aspecto material dessa realização. 


\section{Projetos e educação}

$\mathrm{Na}$ América do Norte (Estados Unidos), foi no início do século 20 que chegaram os projetos de educação com Dewey e Kilpatrick. E pode-se dizer que as definem como atividades intencionais das quais o aluno participa plenamente (Atividade decidida de todo o coração). Proulx (2004) especifica que Kilpatrick defendeu uma pedagogia centrada nos alunos, seus objetivos e suas necessidades. A partir daí, foi necessário desenvolver atividades úteis para eles, orientadas para objetivos concretos e apelando para a capacidade de resolução de problemas. O caminho dos projetos. Parecia a maneira real de alcançá-lo. Encontramos os conceitos de intenção, aqui do aluno, e ação na forma de atividades que são oferecidas aos alunos. Para esses dois precursores, o aluno deve ser um ator em sua formação,

Ao mesmo tempo, os proponentes da Nova Educação (incluindo Freinet, Montessori, Decroly e Makarenko) também queriam promover a construção da aprendizagem pelos próprios alunos, por meio de atividades concretas. Boutinet (2005) indica que o conceito de projeto foi menos utilizado por este último do que por Dewey e Kilpatrick, e caiu em desuso até a década de 1970. Enquanto isso, projetos continuam a ser usados em atividades extracurriculares (teatrais, artísticas, esportivas, científicas, etc. ), mas não cabem na sala de aula (Bru \& Not, 1987).

A democratização da educação, a abertura das escolas à formação de adultos e a crise económica são apenas alguns dos factores, entre outros, de um renovado entusiasmo pelo projecto. Chega por exemplo à Europa, Ásia, nos dias do Ano de 1973 com as experiências (ao nível da turma ou do estabelecimento) resultantes dos $10 \%$ pedagógicos, e desde então tornou-se imprescindível a todos os níveis do sistema escolar, gerando amálgamas entre os campos educacional e pedagógico, instituindo a criatividade (sob risco de matá-la) ou negligenciando que os alunos são os primeiros interessados no projeto (Boutinet, 2005).

\section{Catalogação de projetos em educação}

O primeiro a distinguir vários tipos de projetos foi Kilpatrick em 1921. Para ele, havia quatro tipos de projetos. em um sentido amplo: o primeiro era materializar uma ideia de forma concreta (como escrever uma carta), o segundo era para se apropriar de uma experiência vivida (como ouvir uma peça musical), o terceiro para resolver um problema e o último ( O projeto de aprendizagem) consistia em adquirir conhecimentos através da experiência. Portanto, deu aos projetos um significado muito mais amplo do que o atual, uma vez que o aluno não foi necessariamente ativo em sua aprendizagem, como mostra o segundo tipo de projeto (Helle et al., 2006). No entanto, esta classificação ainda é usada hoje na definição de aprendizagem baseada em projetos, 
Para esclarecer os diferentes significados deste termo na educação, Boutinet (2005) identifica quatro paralelos de projeto, cada um dos quais pode usar pedagogia baseada em projetos, mas não deve ser confundido:

- O projeto formativo, que descreve a condição de unificação dos alunos no universo adulto e cuja função é torná-los autônomos. Esse tipo de projeto vai além do quadro estrito das instituições de ensino.

- O projeto educativo, que intervém na correlação entre professores e alunos, no quadro das instituições de ensino: é o que aqui nos interessa.

- O projeto escolar, que visa apoiar a crescente autonomia das instituições de ensino, alinhando as suas atividades.

- O projeto de formação, que é mais ao nível da formação de adultos, visto a partir do aluno, da organização formadora ou do formador.

Proulx (2004), retomando os quatro níveis descritos por Boutinet por meio do que ele chama de dimensão política ou estratégica de um projeto, acrescenta que outras perspectivas podem ser utilizadas para distinguir projetos, como duração, número de atores (individual, equipe e classe projetos) ou a natureza da principal atividade de aprendizagem envolvida (produção, consumo, resolução de problemas).

O mais próximo possível da definição do projeto como o apresentamos, Crindal et al. (2004) encontram na apresentação oficial do projeto profissional multidisciplinar implementado na escola de formação profissional no início do ano letivo de 2000 (Diário Oficial no 25 de junho de 2000 UNESCO) suas diferentes características presentes em um acúmulo de objetivos que muitas vezes buscam realizações. competitivo. Em diferentes trechos do texto, a vertente existencial persegue três objetivos: a motivação, o envolvimento do aluno ou o seu projeto profissional.

$\mathrm{O}$ aspecto metodológico diz respeito ao processo e ao trabalho em equipe e o operacional se limita à realização e ao resultado concreto. Há, como vimos na definição da palavra projeto, a intenção, o planejamento e o produto final nesses três aspectos do projeto que aqui se apresentam.

\section{Projetos elaborados com abordagens educacionais}

Embora várias teorias e tendências educacionais tenham integrado a abordagem baseada em projetos, é nos países latino-americanos e anglo-saxões que essa orientação tem sido mais sistematicamente organizada e teorizada. Vale destacar aqui a influência de Dewey nos Estados Unidos, em contraposição ao modelo político mais rígido de educação de Durkheim que sempre caracterizou os países asiáticos e europeus. (Meuret, 2007). 


\section{Método dinâmica em treinamento baseado em projeto}

La perspectiva cimentada en la gestión en proyectos, al igual que otras técnicas llamadas, Dinámicas o Activas, se origina efectivamente a inicios del siglo XX en los norme América, donde Dewey arrojó el método de formarse haciendo, que reside en aprender por y en el o que fazer. Sua academia promete ações específicas que devem expressar o desejo inerente à formação dos alunos (Proulx, 2004). Dewey professa que o treinamento deve ser pragmático, e deve instruir os alunos a refletir e se ajustar ao universo em que residem (Mayer \& Alexander, 2011), emergindo de suas conquistas e expandindo sua liberdade. No entanto, ele tinha ambições de passar de um extremo a outro o guia de treinamento usual naquele período, instalando o costume no cerne do aprendizado. Então, veremos abaixo uma família de métodos ativos,

Essa filosofia de educação, assim como a promovida pela Nova Educação em todo o mundo (da qual Decroly e Freinet são os principais protagonistas), mudou a visão da escola de uma perspectiva central do professor para uma perspectiva simétrica do aluno. e perto de sua vida diária. Todos esses métodos ativos são mais do que técnicas de ensino para seus defensores, porque envolvem um repensar fundamental dos fundamentos e da organização da escola, como Dewey pretendia em sua época. A abordagem projetual faz parte desse processo, pois favorece uma abordagem interdisciplinar voltada para os interesses dos educandos e também favorece, como contexto de aprendizagem, situações concretas do cotidiano. (Proulx, 2004).

\section{Aprendizagem baseada em projetos}

É difícil encontrar uma definição única desta abordagem pedagógica. Explicaremos as características comuns apontadas por diferentes pesquisadores que, em sua maioria (em particular autores anglo-saxões, na América Latina apenas replicam) querem enfatizar o ato de aprender falando sobre aprendizagem baseada em projetos. A tradição educacional prefere o termo ensino por projeto, mais raramente o termo ensino por projeto. Perrenoud (2002) considera que os termos foco e foco, aplicados a projetos, são menos invasivos e definitivos do que o termo pedagogia. À parte o termo processo, vemos que o vínculo com o termo projeto é feito antes com a preposição por em vez de onde, provavelmente sublinhando o processo necessário para qualquer implementação de um projeto. Projeto (processo já implícito no processo).

Alguns autores preferem focar na definição do termo projeto e acrescentar, como Mayer e Alexander (2011), que o ato de aprender é focado em projetos, que direcionam as atividades dos alunos. Para Boutinet (2005) essa definição não é suficiente, uma vez que a pedagogia projetual é um cenário efetivo no projeto, insistindo no aspecto metodológico, para além da finalidade do projeto: qualquer projeto educacional não implica necessariamente uma pedagogia por projeto, $o$ que pode ser o caso se os alunos não fizerem o trabalho de apropriação do projeto ou se este lhes for imposto. 
Enfatizando a ligação com a investigação e o papel essencial do professor, Blumenfeld et al. (1991) definem o treinamento baseado em projetos como um aspecto total ajustado no ensino por meio da cooperação do aluno nas explorações realizadas. Dois pontos parecem fundamentais para eles nessa aprendizagem: um problema ou uma questão deve servir de guia para as ações realizadas no projeto, e essas atividades devem conduzir a um produto final que forneça a solução para o problema. Observe que esses dois pontos associam o primeiro e o terceiro tipo de projeto apresentado por Kil Patrick anteriormente, ou seja, materializar uma ideia e solucionar um problema.

Marx et al. (1997) definem cinco características da educação científica baseada em projetos, para dar conta da complexidade desta inovação: uma questão motriz, pesquisa e artefatos, colaboração e ferramentas tecnológicas, proporcionando mais colaboração e TIC, frequentemente utilizadas na prática, mas não necessariamente enfatizado em outras definições.

Proulx (2004) leva em consideração diversas definições para poder dizer que o treinamento baseado em gerenciamento de projetos é, portanto, um conseqüente processo de aproveitamento e transmissão de conhecimentos durante o qual o aprendiz antecipa, planeja e realiza, em um determinado tempo, sozinho ou com colegas e sob a supervisão de um professor, atividade observável que resulta, em contexto educacional, num produto final avaliável.

\section{Tipo de aprendizagem baseada em projeto}

O treinamento baseado em gerenciamento de projetos não deve ser confundido com outros tipos de aprendizagem baseada em investigação, pertencentes à família da aprendizagem baseada em preocupação, incluindo a abordagem de investigação.

A implantação no ensino de ciências no mundo vem sendo reivindicada há alguns anos, e seu objetivo é colocar o aluno na posição de pesquisador. Trata-se de um método especialmente desenvolvido em ciências, visto que se inspira na abordagem científica, já utilizada durante as sessões de trabalho prático. A generalização deste tipo de abordagem também advém da constatação de que as ciências parecem de difícil acesso aos alunos e que estes devem estar mais motivados, envolvendo-os em situações mais concretas e obrigando-os a fazer ciência com as mãos. (Método chamado mãos para trabalhar). O papel do professor nesta aprendizagem é o de tutor (e apoio aos alunos que dele necessitem) para acompanhar os alunos nas fases de questionamento, reflexão crítica, busca de evidências,

O tipo mais famoso de aprendizagem baseada em investigação, que atualmente é muito popular em todos os níveis dos sistemas escolares, é a aprendizagem baseada em problemas (ver em particular Albanese \& Mitchell citados por Savery, 2006, ou a meta-análise de Dochy et al. citado por Barron \& Darling-Hammond, 2010), que está decolando no ensino da medicina e seu diagnóstico. 
Muito utilizado em países anglo-saxões, certamente em comparação com a aprendizagem baseada em projetos, é mais fácil de configurar (por ser menos onerosa no tempo), muitas vezes mais focada na disciplina estudada e mais interessada na aquisição do assunto do que no conhecimento aplicativo. Savery (2006), no Interdisciplinary Journal of Problem-Based Learning que foi criado em 2006 (um sinal de um entusiasmo recente por este método de aprendizagem), especifica que aprender resolvendo problemas permite que os alunos iniciem uma busca em grupo para encontrar juntos um procedimento ou resposta a uma complicação real e complexa e que o professor desempenhe um papel de tutor que orienta o processo de aprendizagem.

Ao contrário do treinamento de projeto, que não permite que os alunos definam e considerem todas as soluções para os problemas que surgem à medida que o projeto avança, a aprendizagem por solução de problemas desenvolve essas habilidades úteis no mundo profissional (Savery, 2006).

A aprendizagem baseada em estudos de caso (é considerada uma forma particular de aprendizagem problematizadora para alguns autores) consiste em estudar diversos exemplos de problemas reais complexos (construídos ou reconstruídos pelo professor) para desenvolver competências como a análise crítica, a tomada de decisões. a ligação entre teoria e prática, ou mesmo adquirir conhecimentos e habilidades em contexto para aplicá-los a outra situação investigativa (Savery, 2006; Mayer \& Alexander, 2011).

Um tipo final de aprendizagem relacionada é a aprendizagem baseada em design, que consiste em desenvolver a aprendizagem projetando e produzindo um produto final (um robô na aula de eletrônica, um edifício em processo de arquitetura, um site durante uma competição, etc.). realizada por tentativa e erro, seguindo a avaliação do objeto em construção em vários momentos durante sua realização. As competências desenvolvidas são de natureza técnica e do tipo cooperação, troca de conhecimentos, planeamento e gestão de limitações. Esse tipo de abordagem é encontrado principalmente em ciência, tecnologia, artes, engenharia e arquitetura (Barron \& DarlingHammond, 2010). Ao contrário da aprendizagem baseada em projetos,

\section{Treinamento cooperativo por meio de projetos}

No projeto de aprendizagem, alunos e alunos aprendem sendo ativos e mantendo uma conexão com o mundo real, permitindo-lhes promover a cooperação, comunicação, criatividade e ideologias profundas. A atenção aos processos de aprendizagem, não apenas ao conteúdo, é benéfica (Barron

\& Darling-Hammond, 2010). Quais são os objetivos perseguidos pelos professores na implementação desta pedagogia? O que deve trazer aos alunos em termos de conhecimentos e competências, motivação e em termos de trabalho entre pares? 


\section{Projetos para construir aprendizagem}

Como Kilpatrick disse já em 1918: Com o educador obviamente social e com o professor hábil para incitar e proteger a sua intenção, alcançamos especialmente aquele tipo de formação que chamamos de construção do caráter. Há germes aqui, além da importância do papel do professor ao qual voltaremos, os elementos essenciais do socioconstrutivismo: o caráter eminentemente social da criança e a construção de seu aprendizado, aqui de sua personalidade.

O aluno tem instruções e habilidades sobre as quais desenvolverá seu propósito. No desenvolvimento efetivo desse projeto, vai construindo gradativamente seu discernimento, cumprindo e corrigindo seus erros, passos necessários que lançam tantas noções novas que o aluno pode recapitular para poder encerrar seu projeto (Perrenoud, 1998). As representações concretas dos benefícios e interrupções dos alunos permitem-lhes trocar, criticar, refletir para a sua melhoria, enfim, aprender: fazer e aprender são indissociáveis (Blumenfeld et al., 1991).

Alguns pesquisadores têm se interessado pelo processo de aquisição de conhecimento de alunos que se deparam com novos dispositivos por meio de uma formação fundamentada em gerenciamento de projetos. O número 39 da revisão Aster, que fornece uma avaliação inicial dos sistemas implementados na escola secundária profissional (o PPCP), nas universidades do mundo (as rotas de descoberta ou IDD. (Baluteau, 2005) e no bacharelado tecnológico (supervisionado trabalho pessoal ou TPE), intitula-se: Novos dispositivos, novos encontros com o saber Nesta ocasião, Larcher e Crindal (2004) utilizam o termo estruturação do conhecimento para designar o processo em que cada aluno se compromete a comparar, ordenar, organizar, aprofundar afirmações heterogêneas, de origem não controlada.

Outra contribuição da aprendizagem baseada em projetos para a construção do conhecimento reside na vinculação e utilização de diferentes formas de conhecimento (abstrato, visual, verbal, etc.), que é geralmente aceito como uma operação complexa para os alunos. Helle et al. (2006) argumentam que a aprendizagem baseada em projetos, baseada no conhecimento de diferentes disciplinas e mesclando teoria e prática, pode ajudar a visualizar as interações entre conceitos difíceis e, assim, facilitar mudanças conceituais e a construção de modelos mentais para melhor compreender esses conceitos.

Em termos de competências, as competências-chave, ou transversais, são as primeiras que pensamos em relação à aprendizagem baseada em projetos, uma vez que geralmente se trata de desenvolver aquelas que não são estritamente disciplinares ou que se assemelham ao mundo profissional. Eles também são conhecidos na literatura como habilidades do século XXI.

Ao enfrentar situações novas e complexas, os projetos podem desenvolver essas habilidades. Para que isso aconteça, deve ser possível praticar o conhecimento dessas habilidades, ou seja, que 
os alunos se apoiem nesse processo. Em uma abordagem de projeto institucionalizada, os alunos podem escolher e transferir os procedimentos já utilizados em uma situação anterior e, assim, aprender a usá-los com sabedoria, levando em consideração os diferentes contextos de cada projeto (Bordalo \& Ginestet, 1993; Proulx, 2004).

\section{Treinamento colaborativo e cooperativo}

Os projetos são transferidos no coletivo dos sujeitos em equipe, mas isso não significa que os alunos aprendam com essa cooperação. Já deve haver cooperação, e não apenas colaboração. A cooperação consiste em ajustar as atividades à situação com vistas a uma efetiva ação conjunta (Marcel et al., 2007, no caso do trabalho docente), enquanto as colaborações se baseiam na declaração e na troca de conhecimentos. Espaço de trabalho para trabalho colaborativo (Marcel et al., 2007). A diferença, portanto, é o trabalho realmente compartilhado na prática da cooperação.

Para que a aprendizagem cooperativa em sentido amplo seja eficaz, Slavin (2010) recomenda que os alunos tenham plena consciência dos objetivos coletivos perseguidos e da sua própria responsabilidade individual: o sucesso do grupo depende da formação característica de cada um de seus alunos. . Acrescenta ainda que a aprendizagem cooperativa aumenta o desempenho dos alunos, independentemente do ponto de vista teórico considerado: motivacional, coesão social, elaboração cognitivo-evolutiva ou cognitiva.

Durante a pesquisa sobre a atividade de um grupo de alunos durante um TPS (trabalho pessoal supervisionado), Andrieu et al. (2003) especificam que, ao contrário de uma situação clássica de ensino-aprendizagem, a construção social do conhecimento ocorre fora da presença do tutor graças a um processamento sociocognitivo desse conhecimento entre os alunos do grupo. E outros parceiros.

A entrevista com o tutor é o lugar e o meio dessa estruturação do conhecimento. Portanto, estão em jogo dois processos: a arquitetura do discernimento, realizada entre os alunos a partir de sua pesquisa documental para determinar a problemática de seu projeto (ponto de partida de qualquer Ambiente Virtual de Aprendizagem - AVA), e a estruturação do conhecimento, realizada na interação entre os grupos e o (s) professor (es) que os supervisionam. A aprendizagem aqui é baseada na cooperação, que ocorre em vários níveis, entre pares e com o professor.

\section{As proposições do treinamento baseado em projetos}

\section{O projeto como fonte de motivação}

Os projetos podem ser usados para aumentar o desejo dos alunos em busca de seu aprendizado. O aspecto concreto dos projetos é a principal fonte de motivação dos alunos, mas certamente não

é suficiente. O professor também deve levar em consideração outros fatores na constituição do seu 
projeto: claro, o interesse que os alunos terão pelo projeto, depois o alcance de suas competências e conhecimentos e por último o fato de que devem permanecer focados na realização do projeto sozinho, e não em competição com outros alunos, o que poderia desviá-los de seu objetivo principal de aprendizagem (Blumenfeld et al., 1991). Na execução do projeto, o professor também deve ser capaz de ajudar os alunos a desenvolver sua autonomia.

\section{Formação específica}

Os projectos, cujo objectivo é produzir um produto final, servem para ligar o que foi aprendido na sala de aula com as experiências vividas fora da sala de aula: alguns investigadores evocam assim a autenticidade, a real natureza dos projectos, uma fonte de motivação, que é ainda mais forte se o aluno escolher seu próprio projeto.

$\mathrm{Na}$ verdade, o conhecimento escolar assim contextualizado ganha legitimidade para os alunos, encontra um significado que os alunos muitas vezes acham difícil atribuir à escola em geral. De acordo com Helle et al. (2006), a teoria cognitivista especifica que, quando aprendemos, retemos implicitamente o contexto de aprendizagem: certos elementos de nosso ambiente podem servir como gatilhos que nos permitem recuperar nosso conhecimento.

No caso do projeto técnico, os alunos assumem diferentes papéis ao longo do projeto, passando de designer a gerente, passando por vendedor ou reparador. Esses diferentes pontos de vista permitem superar a oposição artificial entre escola e vida (Bordalo \& Ginestet, 1993).

O produto final, que vai sendo construído à medida que o projeto avança, permite ao aluno materializar de alguma forma a sua motivação e poder dar feedback regular e progressivo sobre os esforços que dedica ao seu projeto (Proulx, 2004). Em outras palavras, o artefato concreto pode servir como um objeto de fronteira, facilitando a interação contínua orientada para a tarefa entre alunos e professores ou entre colegas. (Helle et al., 2006)

\section{Utilidade e interesse dos alunos no projeto}

O interesse dos alunos, além, é claro, do tema do projeto em si, pode ser de vários tipos. Em primeiro lugar, através do projeto de turma, podem criar, consolidar e refletir sobre o seu projeto pessoal ou profissional, que é de longo prazo e passa por várias fases de maturação, como a concretização de vários projetos.

Perrenoud (2001) especifica que o projeto pessoal não é inato e que na maioria das vezes quem não o tem é perguntado primeiro. Isso é o que ele chama de mandamento paradoxal. A formação de um projeto não é algo feito por encomenda. É algo que você mesmo desenvolve, espontaneamente, porque faz sentido. 
Reconhecer-se como um projeto é uma forma de formular um estado interno de tensão estratégica em direção a um estado desejável. É difícil construir esse sentido por si mesmo, sem participar de uma cultura de projeto que legitime essa forma de relação com o mundo. Se os alunos de certas origens não estão imersos nesta cultura, a escola deve fornecer-lhes os meios para criarem gradualmente o seu projeto individual, socializando-os em projetos coletivos.

O interesse dos alunos reside também na apropriação do projeto: têm o poder de escolher, por exemplo, a forma de apresentação final, desenvolver o seu projeto até certo ponto, determinar as etapas do trabalho, etc. Essa liberdade não é tão comum na sala de aula e o professor deve garantir um equilíbrio justo entre as escolhas dos alunos e os objetivos educacionais definidos antes do projeto (Blumenfeld et al., 1991).

Esse controle que os alunos têm sobre o projeto pode ajudá-los a aprender mais sobre como abordam o conhecimento e os problemas. Na verdade, o tempo dedicado à realização do projeto é útil para que os alunos construam suas próprias representações de aprendizagem, conheçam suas melhores formas de aprender e se responsabilizem por sua aprendizagem (Bell, 2010).

\section{Habilidades iniciais e preparações}

Os alunos podem se sentir desanimados e frustrados se seus conhecimentos e habilidades não estiverem dentro do escopo do projeto e não os permitirem escolher educadamente pesquisas úteis para o desenvolvimento do projeto, ou se as questões a serem resolvidas forem excessivamente complexas para eles. Para lidar com essas dificuldades, os alunos devem ter habilidades cognitivas para serem capazes de lidar com a complexidade inerente aos projetos, e habilidades metacognitivas de dois tipos: táticas para conseguir manter o foco nos objetivos finais do projeto durante os momentos difíceis de realização . e estratégico para apoiar o esforço mental de longo prazo (Blumenfeld et al., 1991).

\section{Conversão da autonomia dos alunos (atores e autores de seu projeto)}

Ao se comprometerem com um projeto, os próprios alunos realizam o seu planejamento e execução: são, portanto, atores do seu projeto e, assim, desenvolvem uma certa autonomia sob o olhar dos colegas e do professor, principalmente em termos de conteúdo e ritmo de trabalho. adoção. Isso os ajuda a adquirir pessoalmente os conceitos e conhecimentos necessários, bem como as habilidades que podem usar para outras situações de resolução de problemas, seja na escola ou não. Mas essa autonomia também vem com a responsabilidade de concluir o produto final mais cedo ou mais tarde, pois os alunos estão comprometidos com essa tarefa. Num exemplo de pedagogia de projeto sobre o tema meio ambiente (Clément \& Guiu, 2000), 
A fase de contacto que se dá em campo e que tira as perguntas dos alunos, a fase de rebatimento na escola que permite que essas perguntas sejam classificadas em diferentes tópicos que os alunos escolhem para realizar na última etapa, ou seja, o fase de estudo e apresentação de suas pesquisas sobre esses temas.

Este artigo estuda a forma como os alunos escolhem para si próprios o tema do seu projeto através das perguntas que colocam durante as fases de contacto e recuperação: verifica-se que os alunos não são completamente autónomos durante esta etapa, uma vez que as suas questões surgem especialmente da interação com os educadores, que conseguem fazê-los emergir sem dar qualquer resposta, afastando-se para deixar o aluno assumir a responsabilidade e ver como sua motivação para um determinado assunto aumenta com o passar do tempo e como as observações. Isso exige que os educadores conheçam em profundidade as possibilidades dos alunos, o campo de estudo das observações e outros projetos já realizados sobre o mesmo tema.

\section{Complexidade no mundo dos projetos}

Ao longo de suas vidas, os alunos enfrentarão problemas sociais e profissionais complexos. Métodos de resolução de problemas e aprendizagem baseada em projetos são uma forma de capturar, ao longo de sua escola, como resolver essas questões espinhosas e obter o conhecimento e as habilidades para lidar com elas (Barron \& Darling Hammond, 2010; Perrenoud, 2002). No curso de bacharelado profissionalizante (até cerca de 4 horas semanais durante dez semanas) reforça os conhecimentos profissionais e gerais aprendidos nas disciplinas, relacionando-os com as práticas profissionais, que os alunos também vivenciam durante os estágios ou períodos. da formação em uma sociedade,

Por exemplo, a adoção de especificações na pedagogia de projetos na educação técnica ajuda os alunos a se apropriarem de uma ferramenta do meio empresarial, como instrumento de previsão, negociação e avaliação de seus projetos, assim como o método de planejamento GANTT utilizado. produção (Bordalo \& Ginestet, 1993). No ensino superior, os alunos, cujo projeto profissional (deveria ser) mais refinado do que nunca, podem até ser contratados para um projeto real por um patrocinador externo.

Para resolver problemas complexos, os alunos devem aplicar um trabalho cognitivo adequado, que não deve ser subestimado. Mesmo um aluno que está altamente motivado e sabe como implementar procedimentos de resolução de problemas pode não querer usá-los e simplificar os problemas com facilidade. É neste nível que o trabalho preliminar e o apoio do professor são decisivos (Blumenfeld et al., 1991). 


\section{Resultados na aprendizagem baseada em projetos}

Muitos dispositivos ditos inovadores introduziram a abordagem do projeto nos programas há pouco mais de duas décadas, em todas as ocasiões de forma interdisciplinar, mas sem banalizá-la (exceto talvez na educação profissional e tecnológica) porque não é assim. Pela maioria dos professores: Esses dispositivos raramente são aplicados porque são ineficazes? Eles são muito difíceis de configurar? Eles invadem as disciplinas a ponto de não estarem apenas fora das disciplinas, mas no seio do aprendizado escolar e, de certa forma, contra as disciplinas (Cauterman \& Daunay, 2010)? Como a abordagem baseada em projetos está se desenvolvendo em diferentes países e diferentes setores? Procuramos fornecer alguns caminhos para a reflexão por meio de vários exemplos e resultados de pesquisas em diferentes níveis de ensino, tendo em mente que medir a eficácia das práticas de ensino é uma questão complexa que depende de muitos fatores (Feyfant, 2011).

\section{Implementação de projeto}

A aplicação da pedagogia baseada em projetos nos países desenvolvidos está se espalhando gradativamente, começando com o estabelecimento na década de 1970 de 10\% projetos pedagógicos, depois culturais e de ação educacional e, em 1981, tanto projetos zonais (quando foram criadas zonas prioritárias de educação) quanto educacionais projetos de ação no ensino médio e na faculdade, depois na escola primária. Em seguida, vem a introdução de projetos técnicos na educação tecnológica em 2018, a seguir projetos multidisciplinares de natureza profissional no ensino médio profissionalizante em 2019, trabalho pessoal supervisionado em instituições de ensino em geral e trabalho transversal no ensino médio no mesmo ano, bem como percursos de descoberta . que irá substituí-los dois anos depois.

\section{Trabalho Pessoal Supervisionado (TPS)}

A pedagogia baseada em projetos, mesmo que não desperte entusiasmo avassalador, permanece, portanto, parte da formação dos alunos em todas as áreas, na forma de dispositivos interdisciplinares. Em 2001, pesquisadores e professores defenderam o TPS, mas tornando a prova no ensino médio opcional e, ao mesmo tempo, é feita uma experimentação do TPS na série tecnológica (Diário Oficial no 24 de junho de 2001, modificado por decreto de Abril de 2002, UNESCO). Em um artigo dessa época, intitulado -TPS ou o impulso quebrado-, Pantanella, professora e treinadora, não esconde sua decepção. Três anos depois, os números confirmam o interesse dos alunos por este sistema: 9 em cada 10 alunos fazem o teste opcional TPS na sessão do ensino médio entre 2004 e 2018 (na Colômbia, Saber PRO Y TyT). 


\section{Treinamento científico baseado em projetos}

O ensino de ciências nas últimas décadas foi objeto de inúmeros debates centrados principalmente no descontentamento dos alunos e na presença desigual de meninas e meninos no campo científico, na necessidade de formar engenheiros para as complexas missões do século XXI ou ainda na disposição para reavaliar a imagem da ciência. Como resultado dessas reflexões, reformas foram iniciadas em vários países, instituindo, entre outras coisas, abordagens ativas em programas de educação científica em todos os níveis. Nesse contexto, podemos citar a implantação do programa no ensino fundamental, iniciada nessa época (Léna, 2009).

Com base em estudos que indicam que a abordagem baseada em projetos ajuda os alunos a compreender os fenômenos científicos encontrados nas aulas de ciências e durante as avaliações padronizadas, Krajcik et al. (2008) constroem nesse contexto de reforma um modelo que torna os objetivos educacionais oficiais esperados consistentes com uma orientação de formação baseada em projetos, testando-o no projeto de pesquisa aplicado em escolas intermediárias (equivalentes a universidades) em todos os países em desenvolvimento.

Os ciclos desta norma são os seguintes: organização dos conteúdos oficiais do programa em diferentes unidades de conhecimento interligadas entre si e preenchidas com os pré-requisitos e as possíveis concepções dos alunos sobre estes temas, tudo numa espécie de mapa conceptual. A seguir, são definidos os principais conceitos necessários para que os alunos adquiram essas unidades de conhecimento (nesta etapa entram em cena os objetivos educacionais perseguidos pelo projeto), desdobrando-se no mapa formado. O próximo passo fundamental é definir os diferentes desempenhos de aprendizagem que, combinando os conceitos mencionados acima (como as reações químicas criam novas substâncias que não têm as mesmas propriedades das substâncias que reagiram juntas) com o raciocínio.

Cientistas associados (como Realizando um processo de pesquisa e Usando as técnicas e instrumentos necessários para coletar dados) podem operacionalizar o processo científico dos alunos e localizar seu conhecimento (neste exemplo, o desempenho de aprendizagem pode ser Construir um processo de pesquisa). para coletar dados sobre os pertences das substâncias e efeitos da reação química). A fase de desenvolvimento consiste então em contextualizar o projeto, definir os objetivos de aprendizagem da etapa anterior, construir uma sequência didática coerente que irá orientar o aluno tarefa após tarefa ao problema proposto pelo projeto e pensar numa avaliação para cada uma delas. tarefa, siga tão de perto quanto possível (atenção iterativa) o envolvimento dos alunos nessas tarefas.

Este caso extremo de apropriação do currículo e orientação dos alunos mostra que, para que uma mudança de abordagem pedagógica seja eficaz (e é o caso das turmas avaliadas), isso implica necessariamente uma releitura das normas na perspetiva dos professor já partindo da paisagem do 
aluno, uma tradução dos objetivos educacionais em desempenho de aprendizagem, incluindo raciocínio científico, e atenção sustentada ao vínculo entre objetivos educacionais, tarefas a serem realizadas e avaliação.

\section{Efeitos da metodologia nos alunos}

Estudos de métodos de pesquisa geralmente indicam que, embora em alguns casos não haja inferências na produtividade do aluno, certos tipos de habilidades ainda são desenvolvidos com esses métodos. Tipos de alunos muito diferentes (Barron \& Darling-Hammond, 2010).

Helle et al. (2006) qualificam este ponto: os estudos que revisaram são em sua maioria limitados a descrições de implementação de projetos sem um arcabouço teórico sólido, e muitas vezes são escritos por projetistas ao invés de pesquisadores educacionais, e estão longe de serem precisos sobre as condições metodológicas utilizadas. No entanto, é de notar que estes autores limitam a sua revisão da literatura (realizada entre 2001 e 2016) ao ensino superior e que, sobretudo, como já referimos, mostrar a eficácia de uma prática educativa sobre outra implica necessariamente dificuldades de termos de ordem metodológica (Proulx, 2004; Feyfant, 2011).

\section{Avaliação e projetos}

Como qualquer dispositivo que requer habilidades ou depende (na maioria dos casos) de várias disciplinas, a aprendizagem baseada em projetos delineia muitos problemas de avaliação, uma vez que não está enquadrada no selo formal de avaliação tradicional em cada disciplina porque nem todos os alunos são treinados em da mesma forma e ao mesmo tempo (Marx et al., 1997; para uma reflexão mais geral sobre avaliação.

Em primeiro lugar, a avaliação da conclusão real do projeto pode ser feita na forma de uma avaliação somativa. A apresentação do projeto pelos alunos, bem como os conhecimentos adquiridos, podem, por exemplo, ser avaliados tanto pelo professor como pelos seus colegas. É o mesmo tipo de avaliação que se encontra para a apresentação oral das muitas provas pedagógicas do mundo, avaliadas por um júri de professores de duas disciplinas diferentes e que não acompanharam o trabalho dos alunos durante o ano (Diário Oficial $\mathrm{n}^{\circ} .41$ de novembro de 2005, Anexo 1 da UNESCO). Alguns autores também insistem na avaliação ex post do projeto, o que deve permitir aos professores (e alunos) enfrentar melhor os projetos futuros. Esta reflexão pode, por exemplo,

Mas isso não é suficiente para este tipo de aprendizagem, uma vez que a apresentação pode apenas refletir o trabalho em grupo e não levar em conta o trabalho real de cada aluno, o que parece ser uma das dificuldades clássicas dos professores quando se deparam com a aprendizagem em grupo. 
Uma das respostas a esta questão reside no uso de ferramentas de avaliação formativa. Vários pesquisadores, incluindo o Buck Institute for Education (2012), Recomenda-se a realização de um relatório de andamento dos trabalhos, individualmente e em equipes (na forma de um diário de bordo ou pasta, também chamado de arquivo de aprendizagem), relatado pelos alunos. eles mesmos; ou grades de avaliação a serem preenchidas pelos professores, mas tornadas explícitas e acessíveis aos alunos ao longo do projeto.

Outros pesquisadores como Bordalo e Ginestet (1993) preferem o termo avaliação formativa (mantendo a avaliação formativa para medir o cumprimento dos microbjetivos da pedagogia por objetivos), vinculado a uma concepção cognitiva, e em que o aluno representa a meta A atingir, planeje a ação com antecedência e pratique o autocontrole.

São apresentadas algumas formas de autoavaliação (em brochura em anexo elaborada pela Secretaria de Educação Escolar do Ministério da Educação a partir de uma obra coletiva) para a implementação de projetos em escolas secundárias e profissionais, mas fora das avaliações disciplinares e transversais. realizadas primeiramente por professores em suas disciplinas ou em conjunto, e contando para controle durante o treinamento (ou seja, para diploma profissional) também podem ser consideradas (Diário Oficial nº 25 de junho de 2000 UNESCO).

Por outro lado, não é possível recorrer à autoavaliação ou coavaliação das provas, cuja pontuação está relacionada com a abordagem pessoal e investimento do candidato durante a preparação do TPS, bem como a "resposta a o problema (correspondente à produção final) No entanto, um pouco mais pesquisadores concordam que a avaliação de um projeto deve formar uma estrutura bem fundamentada e constituída em uma direção ascendente, e não pode ser feita posteriormente (Krajcik et al., (2008 ); Blumenfeld et al., 1991).

\section{Resultados e conquistas nos alunos}

Uma primeira abordagem muito gradual para ver se uma técnica educacional é positiva é comparar as consequências comuns dos alunos com as de um grupo de controle. Por exemplo, em um estudo com 111 alunos da oitava série (equivalente ao terceiro ano do ensino médio) que participaram de um projeto para criar uma casa de bonecas para crianças menores de 10 anos constatou, entre outras coisas, que as derivações dos alunos no teste de geometria padrão aumentado em pelo menos $10 \%$, independentemente do nível do aluno testado:

Apresentamos evidências de que os alunos aprenderam conceitos geométricos baseados em padrões, que aprenderam a comunicar suas ideias, que se beneficiaram com o processo de revisão e que seu trabalho nesses problemas e projetos foi memorável. De referir ainda neste estudo que os projectos são precedidos de exercícios de treino na resolução de problemas, por exemplo, na forma 
de vídeos que apresentam um problema a resolver, para que os alunos se habituem, em situações menos complexas, à procura de soluções como um grupo (Chu, 2009), para um estudo com crianças do ensino fundamental na América Latina.

Também há maior familiaridade e facilidade de uso de procedimentos matemáticos para esses alunos. Esses resultados se devem, segundo a autora, às práticas pedagógicas e à escolha do programa de ensino pelos professores.

Krajcik et al. (1998), em estudo sobre a implementação da abordagem de projeto por alunos do $7^{\circ}$ ano (equivalente ao $7^{\circ}$ ano) em física e química, indicam que esses alunos, em condições normais de uma aula normal, são capazes de realizar Reflexão sobre profundidade e planejar corretamente o seu projeto, mas que a natureza científica das suas dúvidas e o rigor exigido no processamento de determinados dados nem sempre estiveram presentes. Por outro lado, esses alunos ficam tão entusiasmados durante o projeto que os autores se perguntam como manter esse interesse pelo resto da aula de ciências.

Tendo acompanhado alunos de graduação por dois anos realizando projetos de modelagem em astronomia com software de visualização 3D, Barab et al. (2000) mostram com a ajuda de questionários, observações de aulas e entrevistas que esses alunos constroem seus conhecimentos de astronomia durante a fabricação de modelos de realidade virtual, conhecimento este situado no que se refere à própria experiência dos alunos e que estes retêm melhor do que em cursos de astronomia usando livros didáticos.

Os outros estudos sobre a eficácia da aprendizagem baseada em projetos são mencionados em particular nas revisões da literatura de Barron e Darling-Hammond (2010): alunos do ensino fundamental têm melhor desempenho em um teste de reflexão crítica e alunos obtêm melhores resultados. realizações (método utilizado por um grupo de controle e realizado por Shepherd, citado por Barron e Darling-Hammond, 2010). Aprendizes adultos na agricultura ganharam autoconfiança, ganharam conhecimento e mudaram a forma como abordam seu trabalho (Fell, citado por Helle et al., 2006).

\section{Tipo de motivação para projetos}

A aprendizagem baseada em projetos requer um comprometimento significativo dos alunos, que será sustentado por um longo prazo. Portanto, sua motivação e o apoio do professor são necessários para o sucesso do seu projeto. Mas esse método realmente aumenta a motivação do aluno? Muitas pesquisas têm mostrado que a aprendizagem para resolução de problemas tem um efeito positivo na motivação: muitos pesquisadores pegaram esses resultados e os aplicaram à aprendizagem baseada em projetos (Barron \& Darling-Hammond, 2010), e há poucos estudos reais sobre a ligação entre motivação e aprendizagem baseada em projetos (Helle et al., 2007). 
Portanto, esses autores estão interessados na motivação intrínseca e nos processos cognitivos implementados por aproximadamente sessenta alunos do terceiro ano de ciências da informação que investiram em um projeto pré-profissional de sete meses. Estes alunos foram previamente classificados de acordo com o nível de autorregulação da sua aprendizagem e são submetidos a questionários antes e após as sessões de aprendizagem do projeto. Los resultados indican que la exaltación específica de los educandos aumenta fuertemente en el grupo de prueba (que va en la dirección de los estudios sobre el aprendizaje basado en problemas), mientras que los indicadores que miden los procesos cognitivos son similares en los dos grupos y no tempo.

\section{Conflitos de aplicativos específicos}

Krajcik et al. (1998) especificam a categoria de expansão dos arquétipos de recursos para ajudar os alunos a gerenciar a confusão de um projeto: reações com o professor, que são conclusivas para a responsabilidade do aluno, interações com colegas e suporte de TIC, para verificar a relevância e validade científica de seu raciocínio .

\section{Principais funções dos professores no treinamento ABPr}

Muitos professores relutam em usar o treinamento baseado em projetos em sua sala de aula. Depois de todas as evidências apresentadas, pode-se indicar que existem três razões principais para essa falta de entusiasmo:

- O medo da decepção, entre o momento de lançamento deste novo método de intervenção educativa em condições materiais que podem ser limitadas e o tempo efetivamente alocado a este projeto.

- Aderência parcial a determinados postulados de formação com base na gestão de projetos, como a necessária ativação do aluno, o que não parece relevante para todos os conceitos a serem percorridos; e como o fato de que todos os alunos devem estar interessados no mesmo projeto, o que obviamente não parece viável.

- Resistência à necessidade de mudança de práticas tradicionais, que não parecem tão ineficazes, e que os leva a usar uma técnica em vez de outra dependendo da matéria de ensino.

\section{Autonomia e responsabilidade do aluno}

O aluno é responsável pelo seu projeto, pois é ele quem constrói o seu conhecimento. Portanto, o professor deve deixá-lo agir sozinho, apoiando-o. Mas isso não é fácil de fazer, uma vez que os professores têm que gerenciar uma organização material diferente da classe; e uma vez que devem ser capazes de apoiar todos os grupos ao mesmo tempo, independentemente de seu progresso no projeto. Finalmente, os professores muitas vezes sentem a necessidade de monitorar e direcionar a 
aprendizagem de seus alunos para garantir que eles tenham entendido corretamente, mesmo sabendo que a construção da própria aprendizagem é essencial (Marx et al., 1997).

Quando o professor segue os projetos de seus alunos, tende a tentar economizar tempo e fazêlos poupar certas tentativas de tentativa e erro ou acelerar o processo por não permitir que formulem as diferentes etapas de seu estudo. Mas são precisamente esses estágios e essas tentativas que estão no cerne da aprendizagem (Bordalo \& Ginestet, 1993).

\section{Auxiliar, proteger e apoiar a motivação dos alunos}

Durante o projeto, o professor permanece, é claro, o especialista em conteúdo do projeto. Dumas e Leblond (2002) apontam que o professor assume diferentes papéis no quadro da pedagogia do projeto: um motivador, sabe promover a intervenção dos alunos em outras ações formativas. Além disso, como mediador, provoca o aparecimento de conflitos cognitivos e sociocognitivos nos alunos. Mas, acima de tudo, é ele quem desempenha o papel de guia, de companheiro no caminho da aprendizagem. É sua responsabilidade assegurar as ligações entre o currículo e o projeto.

Proulx (2004) especifica ainda esses papéis: o professor deve primeiro ser um treinador para exercer sua experiência e tomar as decisões mais importantes que são necessárias, enquanto gerencia o risco e a incerteza devido ao projeto; Ele também deve desempenhar o papel de facilitador, prestando atenção nas ações de todos os alunos e monitorando a prontidão em sala de aula; em seguida, um papel de motivador, para apoiar e encorajar a motivação do aluno ao longo do projeto; e, por fim, um papel de avaliador, que também inclui feedback sobre o aprendizado de cada aluno ao final do projeto.

\section{Treinamento abrangente em projetos}

As mudanças na prática profissional no âmbito dos métodos de pesquisa são feitas em pequenos passos, quando os professores estão interessados em testar um dos pontos fortes da aprendizagem informada em gerenciamento de projetos, como a motivação ou colaboração dos alunos, sem realmente saber o que os espera (Marx et al, 1997; Toolin, 2004). Como qualquer mudança na prática, leva tempo e a progressão não é linear.

O alinhamento dos professores neste protótipo de competências inovadoras, por exemplo, nos Estados Unidos após a transformação do período dos anos 90, teve que ser feito levando em consideração o seu ambiente e promovendo uma mudança sistêmica: $O$ desenvolvimento profissional do professor eficaz deve ser com base em um modelo de crescimento e desenvolvimento de professores que reconhece as complexidades da sala de aula, a escola e a comunidade como ambientes e contextos de trabalho docente. (Marx et al., 1997). 
Esses autores recomendam que o treinamento se concentre em quatro pontos particulares: colaboração com pesquisadores, planejamento da implementação de suas práticas inovadoras, levando em consideração todos os aspectos de um projeto (avaliação, conteúdo de aprendizagem, organização geral, etc.), o tempo necessário para ancorar o projeto - aprendizagem baseada em habilidades diárias (e não tentar dois ou três projetos e depois parar), abstração e observação da prática. Para isso, esses pesquisadores desenvolveram uma plataforma interativa (hoje com 15 anos) que inclui ferramentas para auxiliar na realização e vídeos de exemplos de execução de projetos, sem falar em um espaço de intercâmbio para professores.

Plataformas semelhantes estão sendo desenvolvidas, como a da Fundação Georges Lucas, Edutopia (veja sua revisão da literatura atualizada sobre aprendizagem baseada em projetos), ou como o site do Buck Institute for Education e seus recursos para professores. Existem também softwares de gerenciamento de projetos (e mapas conceituais), que são usados principalmente em negócios, mas podem ser adaptados para o trabalho dos professores (Blumenfeld et al., 1991).

\section{Estruturação de projetos}

Um dos maiores desafios que os professores enfrentam ao implementar um projeto é o tempo: o tempo gasto no projeto muitas vezes parece muito longo em comparação com o tempo normalmente gasto em um conceito. Isso se deve ao fato de que os conceitos abordados no projeto são complexos e interligados, enquanto o ensino por objetivos divide o conhecimento. O Buck Institute for Education (2012) sugere, neste caso, modificar o projeto ao longo do caminho (por exemplo, simplificando um pouco, direcionando os alunos mais para uma tarefa específica, compartilhando os mesmos recursos entre grupos diferentes).

Mas por trás dessa dificuldade, muitas vezes está a pressão social do programa para que seja concluído a todo custo, assim como as provas nacionais ou regionais que são aplicadas aos alunos. Como vimos, o papel do professor é fundamental, em particular na forma como escolhe o projeto e o problema: os professores devem selecionar cuidadosamente as questões motrizes para garantir que as investigações dos alunos lhes permitam aprender o conteúdo científico estipulado em as estruturas curriculares. "(Marx et al., 1997). Portanto, muitas vezes há tensões entre a aprendizagem baseada na gestão de projetos, currículos oficiais e avaliação nacional (Krajcik et al., 2008):

- Os conhecimentos exigidos para um determinado projeto podem ultrapassar os conhecimentos de cada disciplina em questão e o tratamento desses conhecimentos não será efectuado na ordem prevista.

- É preciso ter certeza de que a distribuição de conteúdos ao longo do ano no âmbito da aprendizagem baseada na gestão de projetos abrange o programa oficial. 
- Como conciliar o contexto específico de aprendizagem baseada na gestão de projetos e a abordagem mais abrangente desejada pelo programa?

Além disso, não basta fazer um projeto autêntico (Barron et al., 1998), devemos pensar no projeto através dos objetivos de aprendizagem. Helle et al. (2006) apontam que não deve haver muitos objetivos em um mesmo projeto, para que sejam alcançáveis pelos alunos: a estruturação de um projeto é, portanto, uma etapa muito importante e delicada de se realizar, pois é necessária articular objetivos de aprendizagem, vínculos com programas e avaliações nacionais, diferentes tipos de avaliações, interesse dos alunos pelo projeto.

\section{Suporte em ambientes de treinamento de projetos}

Tomemos um exemplo hipotético: alguma reforma educacional (renovação educacional) introduziu uma nova forma de operar nas escolas e a colaboração tornou-se, de certa forma, uma exigência; O que se espera de uma equipe escolar é ter um projeto educativo no qual, de forma coerente e reflexiva, estejam inseridas práticas pedagógicas que envolvam seus alunos, principalmente na pedagogia de projetos. (Lanaris \& Savoie-Zajc, 2010 consideram que a eficácia da pedagogia projetual implementada pelos professores depende da implementação a nível coletivo, em cada estabelecimento, e portanto da articulação entre os diferentes projetos em torno do projeto escolar, todos eles que deve ser semelhante ao modelo de organização de aprendizagem para ser eficaz.

Huber (2005) propõe como condições de efetivação da pedagogia do projeto (além das condições de gestão do projeto no tempo pedagógico e a condução didática da aprendizagem que são de responsabilidade do professor) uma cooperação na vida. do professor, do estabelecimento (através do seu projeto geral) e de um ambiente amplo, como a abertura do estabelecimento a pessoas com recursos externos que possam intervir na sala de aula.

Por sua vez, Barab et al. (2000) desenvolveram seu estudo sobre realidade virtual em astronomia no que eles chamam de ambiente de aprendizagem participativo, rico em tecnologia, baseado na investigação e que tem as características de proporcionar aos alunos meios para trabalharem juntos: meios tecnológicos que apóiem sua pesquisa, e ambiente propício à aprendizagem autêntica, espaços pensados para o trabalho em equipe.

Esse ambiente tem para eles a capacidade de apoiar o aprendizado dos alunos de astronomia. Marx et al. (1997) acrescentam que o estabelecimento deve ter meios para criar coletivamente as condições ideais para a realização de projetos: No nível escolar, inclui programação em bloco para permitir a investigação, ênfase no trabalho interdisciplinar, aquisição e fácil acesso a computadores e assistência técnica e formação, bem como a implementação de novas formas de avaliação. 
A aprendizagem baseada em projetos traz muita esperança para a educação: ao construir o conhecimento dos alunos de uma perspectiva individual e profissional, ao mesmo tempo introduzindo-os no trabalho em equipe e assumindo responsabilidade e autonomia, parece motivadora e formativa, mas pode revelar-se ineficaz quando os cuidados não são tomados para estruturar o projeto, apoiar a motivação e apoiar o professor. A aprendizagem baseada em projetos está causando uma mudança profunda, uma mudança que já está em curso no sistema educacional, e que se fala em projetos há cerca de trinta anos, e que está se efetivando em vários países e em certos setores próximos ao mundo profissional . 


\section{Referências}

Andrieu, B., Bourgeois, I., Gaspar, É. e Renauld, Y. (2003). Estruturação do conhecimento: alunos e professores do ensino médio envolvidos em trabalho pessoal supervisionado. Aster, 36. Ardoino, J. e Berger G, (1989). De uma avaliação desmoronando a uma avaliação em ação: o caso das universidades. Vine: Matrix: ANDSHA

Baluteau, F. (2005). Que dispositivos interdisciplinares eles introduzem nas universidades? Centros educacionais, $\mathrm{n}^{\circ} 19$.

Barab, S., Hay, KE, Barnett, M. e Keating, T. (2000). Projeto de sistema solar virtual: construindo compreensão por meio da construção de modelos. Journal of Research in Science Teaching, Flight. 37, no.7.

Barron, B.JS., Schwartz, DL, Vye, NJ et al. (1998). Doing with Understanding: Lições da Pesquisa sobre Aprendizagem Baseada em Problemas e Projetos. The Journal of Learning Sciences, Flight. $7, \mathrm{n}^{\circ} 3$ e 4.

Barron Brigid e Darling-Hammond Linda (2010). Perspectivas e desafios dos métodos de aprendizagem por investigação. "No CERI. Como aprendemos? Pesquisa a serviço da prática. Paris: OCDE.

Bell, S. (2010). Aprendizagem baseada na gestão de projetos para o século 21: competências para o futuro. A Câmara de Compensação, Voo. 83, no 2, p. 39-43.

Boaler J. (1998). Matemática fechada e aberta: experiências e compreensões dos alunos. Journal of Research in Mathematical Education, Flight. 29, $\mathrm{n}^{\circ} 1$.

Boaler J. (2002). Aprendendo com o ensino: explorando. a relação entre reforma curricular e equidade. Journal of Research in Mathematical Education, Flight. 33, no.4.

Boutinet, JP. (2005). Antropologia do projeto. Paris: University Press.

Bórdalo, I. e Ginestet, J. - P. (1993). Para uma pedagogia do projeto. Paris Hachette.

Diário Oficial no 24 de junho de 2001, modificado pelo decreto de abril de 200 da UNESCO).

Diário Oficial $\mathrm{n}^{\circ} 4$ de junho de 2010, modificado pelo decreto de abril de 2012 (UNESCO).

Blumenfeld, PC, Soloway, E., Marx, RW et al. (1991). Motivar a aprendizagem com base na gestão de projetos: sustentando o fazer, apoiando a aprendizagem. Psicólogo Educacional, Flight. $26, \mathrm{n}^{\circ} 3$.

BruMarc e Not Louis (1987). Para onde vai a pedagogia do projeto? Toulouse: Ed. Academicos del Sur

Cauterman, M. - M. e Daunay, B. (2010). A selva de dispositivos. Investigue, $\mathrm{n}^{\circ} 52$.

Champy P. \& Etévé, C. (2005). Dicionário Enciclopédico de Educação e Treinamento. Paris: Retz.

Clément, P. e Guiu, F. (2000). Pedagogia e projeto de educação ambiental: de onde vêm as dúvidas dos alunos do CM2 em campo? Aster, $\mathrm{n}^{\circ} 31$.

Crindal Alain, GM- F., Hartoin, A.-M. e Jouin, B. (2004). Qual é o processo de estruturação do conhecimento durante o projeto profissional multiprofissional no ensino médio profissional? Aster, no 39 . 
Dumas, B. e Leblond, M. (2002). Os papéis do professor na pedagogia de projetos. Quebec francês, $\mathrm{n}^{\circ} 126$.

Feyfant, A. (2011). Os efeitos das práticas de ensino na aprendizagem. Arquivo Temático de Revisão de Análise, $\mathrm{n}^{\circ} 65$.

Helle, L., Tynjala, P. e Olkinuora, E. (2006). Aprendizagem baseada em projetos na educação póssecundária - teoria, prática e elásticos. Ensino superior, voo. $51, \mathrm{n}^{\circ} 2$.

Helle, L., Tynjälä, P., Olkinuora, E. e Lonka, K. (2007). Não é nada parecido com a coisa real. Motivação e Processos de Estudo em um Curso de Projetos Baseados no Trabalho em Projeto de Sistemas de Informação - British Journal of Educational Psychology, Flight. 77, $\mathrm{n}^{\circ} 2$.

Ferramenta em Regina E. (2004). Alcançando um equilíbrio entre inovação e padrões: um estudo de professores que implementam abordagens baseadas em projetos para o ensino de ciências. Jornal de educação científica e tecnologia, Flight. 13, 2.

Huber, M. (2005). Faça um projeto de aluno. Paris.

Buck Institute of Education (2012). Aprendizagem baseada em gerenciamento de projetos no ensino médio. Guia prático para planejar e realizar projetos com seus alunos. Montreal: Chanelare Education.

Krajcik, JS, Blumenfeld, PC, Marx, RW et al. (1998). Pesquisa em sala de aula de ciências baseada em projetos: tentativas iniciais de alunos do ensino médio. The Journal of Learning Sciences, Flight. $7, \mathrm{n}^{\circ} 3$ e 4 .

Krajcik J., Mc Neil, KL e Reiser, BJ (2008). Modelo de design baseado em objetivos de aprendizagem: desenvolvimento de materiais curriculares que se alinhem com os padrões nacionais e incorporem pedagogia baseada em projetos. Educação científica, voo. 92

Lanaris, C. e Savoie-Zajc, L. (2010). Equipes escolares em projeto: os múltiplos níveis de colaboração. Em Corriveau Lise, Letor Caroline, Périsset-Bagnoud Danièle e Savoie-Zajc. Lorraine. Trabalhe junto em estabelecimentos de ensino e treinamento. Bruxelas.

Larcher, C. e Crindal, A. (2004). Novos dispositivos, novos encontros com o conhecimento. Aster, $\mathrm{n}^{\mathrm{o}} 39$.

Léna P. (2009). A aventura da prática. International Journal of Education Services 51,

Marcel, J. - F., Dupriez, V., Périsset - Bagnoud, D., \& Tardif, M. (2007). Coordene, colabore, coopere. Novas práticas de ensino. Bruxelas: De Boeck.

Marx, RW, \& Blumenfeld, PC, Krajcik, JS e Soloway, E. (1997). Representação da ciência baseada em projetos. O jornal da escola primária, Flight. $97, \mathrm{n}^{\circ} 4$,

Mayer, RE e Alexander, PA (2011). Manual de Pesquisa sobre Aprendizagem e Instrução Nova York: Routledge.

Meuret, D. (2007). Ele governa a escola. Uma comparação entre a França e os Estados Unidos. Paris: Editora Universitária da França.

Perrenoud, P. (1998). Teve sucesso ou entendeu? Os dilemas clássicos de uma abordagem de projeto. Genebra: Universidade de Genebra. Em linha.

Perrenoud, P. (2001). O projeto pessoal do aluno, uma ficção? Universidade de Genebra. 
Perrenoud, P. (2002). Aprender na escola por meio de projetos: por quê? Como? 'o que? Educador, $\mathrm{n}^{\circ} 14$.

Proulx, J. (2004). Aprendizagem baseada em projetos. Sainte-Foy: Prensas da Universidade de Quebec.

Savery JR (2006). Visão geral da aprendizagem baseada em problemas: definições e distinções. Revista Interdisciplinar de Aprendizagem Baseada em Problemas, Voo. $1 \mathrm{n}^{\circ} 1$.

Slavin Robert E. (2010). Aprendizagem cooperativa: por que funciona? na CERI. Como aprendemos? Pesquisa a serviço da prática, paris OCDE. 